\title{
VIOLÊNCIA CONTRA A MULHER: COMO OS PROFISSIONAIS NA ATENÇÃO PRIMÁRIA À SAÚDE ESTÃO ENFRENTANDO ESTA REALIDADE?
}

\begin{abstract}
Silvana Cavalcanti dos Santos
Docente no Instituto Federal de Ciências, Educação e Tecnologia de Pernambuco (IFPE) Campus Pesqueira; Docente do Programa de Pós-graduação em Saúde Pública da Escola Superior de Saúde de Arcoverde (ESSA) Brasil.
\end{abstract}

\section{Patricia de Albuquerque Barros}

Enfermeira graduada nas Escola Superior de Saúde de Arcoverde (ESSA) Brasil.

\section{Rafaella França de Araújo Delgado}

Enfermeira graduada nas Escola Superior de Saúde de Arcoverde (ESSA) Brasil

\section{Luiza Vanessa de Lima Silva}

Enfermeira graduada nas Escola Superior de Saúde de Arcoverde (ESSA) Brasil.

\section{Valdirene P. da Silva Carvalho}

Docente do Curso de Bacharelado em Enfermagem do Instituto Federal de Educação Ciências e Tecnologia de Pernambuco (IFPE) Campus Pesqueira, Brasil.

\section{Ana Carla Silva Alexandre}

Docente do departamento de Enfermagem do Instituto Federal de Educação, Ciência e Tecnologia de Pernambuco (IFPE) Campus Pesqueira; Docente do Programa de Pós-graduação em Saúde Pública do Centro Universitário do Vale do Ipojuca (Unifavip-Devry) Caruaru (PE) e do Programa de Pós-graduação em Enfermagem em Urgência e Emergência da Escola Superior de Saúde de Arcoverde (ESSA) em Arcoverde (PE), Brasil.
Autor correspondente:

Silvana Cavalcanti Santos

E-mail: annacavalcanty@gmail.com
RESUMO: A violência contra a mulher é um grande problema que entra na esfera da saúde por afetar fortemente às mulheres, podendo causar mortes, traumas físicos, agravos mentais, emocionais, espirituais e diminuir a qualidade de vida. Desse modo, o estudo objetiva identificar as formas de assistência prestada pelos profissionais da atenção primaria à mulher vítima de violência no município de Buíque (PE). Trata-se de um estudo exploratório-descritivo, de abordagem qualitativa, desenvolvido junto a 11 enfermeiras que compõem a atenção primária à saúde de Buíque (PE). A coleta de dados foi realizada nos meses de maio e junho de 2017 por meio de entrevista semiestruturada, gravada e transcrita. Por meio da análise de conteúdo, foram identificadas as seguintes categorias: falta de estrutura das unidades, de capacitação dos profissionais e de uma rede de proteção a essas mulheres. Concluiu-se que são necessárias capacitações para os profissionais que compõem as equipes a fim de que eles sejam capazes de ofertar uma assistência integral a essas mulheres.

PALAVRAS-CHAVE: Violência contra a mulher; Cuidados de enfermagem; Saúde pública; Saúde da mulher; Acolhimento.

\section{VIOLENCE AGAINST WOMEN: HOW ARE HEALTH CARE PROFESSIONALS COPING WITH THE ISSUE?}

\begin{abstract}
Violence against women is a terrible issue, within the health sphere. It affects females, causing death, physical traumas, mental, emotional and spiritual damage, with a decrease in life quality. Current exploratory, descriptive and qualitative analysis identifies assistance given by 11 health professionals to the female victims of violence in Buique PE Brazil. Data were collected during May and June 2017 through a half-structured interview which was recorded and transcribed. Content analysis identified the following categories: lack of structure in care units, lack of capacity of health professionals and absence of protection for these women. Upgrading professionals that form health teams is imperative so that they may be able to offer integral assistance to the victims.
\end{abstract}

KEY WORDS: Violence against women; Nursing Care; Public Health; Women'S Health; User Embracement .

\section{INTRODUÇão}

De acordo com a Organização Mundial da Saúde (OMS), violência é entendida como uso de força física ou poder, em ameaça ou 
na prática, contra si próprio, outra pessoa ou contra um grupo ou comunidade que ocasione ou venha ocasionar em sofrimento, agravo psicológico, desenvolvimento prejudicado, privação e até levar a morte ${ }^{1}$.

A OMS estima que no mundo, uma em cada três mulheres é, já foi, ou será vítima de violência doméstica 2. O "Mapa da Violência 2015: Homicídio de Mulheres no Brasil" ${ }^{3}$ revela aumento de $252 \%$ de mulheres vítimas de assassinato no país no período de 1980 a 2013. Esses dados refletem nas estatísticas de mortalidade, indicando que uma mulher é morta a cada 02 horas no Brasil ${ }^{4}$.

A violência contra mulher (VCM) é um problema que ocorre no mundo todo, uma evidente problemática principalmente por causar diversos danos à vítima, entre eles a morte 5 . Uma questão com implicações significativas, no que se refere ao gênero, é a violência, sobretudo a sexual. Estudos apontam que, no Brasil, a agressão contra a mulher tornou-se um motivo de preocupação que gradativamente vem transformando em um dos novos perfis epidemiológicos do país ${ }^{6}$.

A violência, principalmente quando se refere à mulher, entra na esfera da saúde por afetar fortemente grande parcela da população feminina, como já mencionado podendo levar a traumas físicos, agravos mentais, emocionais, espirituais e diminuir a qualidade de vida ou até mesmo a morte. Tal constatação exige uma reorganização dos serviços de saúde para atenção a essas mulheres. E os profissionais de saúde devem apropriar-se de novos saberes nas diversas áreas do conhecimento, bem como das discussões interdisciplinares e intersetoriais para subsidiar e aprimorar na prática do cuidado em saúde ${ }^{7,8}$.

Os profissionais de saúde apontam algumas dificuldades para atendimento às mulheres vítimas de violência entre elas, destacam-se o constrangimento da mulher em procurar o serviço ou até mesmo em fornecer informações necessárias para melhor acompanhamento, às deficiências da rede de saúde, a desinformação da vítima de violência (por perceber a violência como natural), a escassez de recursos humanos e materiais capacitados para prestarem atendimento à mulher em situação de violência ${ }^{9,10,11}$.

Portanto, embora haja investimento das três esferas de governo para atenção às mulheres em situação de violência, são inevitáveis e persistentes as dificuldades dos profissionais de saúde neste atendimento, principalmente quando se refere à violência. Todavia, o Ministério da Saúde reconhece que esses profissionais de saúde da rede de atenção primária estão em arranjo estratégico para o diagnóstico e atuação neste problema, já que oportunizam espaço de denúncia, de assistência e de proteção. Eles também são os principais responsáveis pela instituição de vínculos de confiança dos usuários com os serviços, fator importantíssimo na prevenção, na busca precoce de orientação, na garantia e qualidade de apoio e na eficácia da assistência ${ }^{8}$.

Desse modo, perante a problemática apresentada, bem como da carência de estudos em relação à atuação profissional no acolhimento à mulher vítima de violência há pouco identificada nos serviços de saúde e subnotificada dos casos VCM, mascarando a gravidade da situação, já que não se tem o conhecimento sobre a extensão do problema, na qualidade e no alcance de programas de prevenção ${ }^{2,12}$.

Diante desta realidade busca-se compreender como é prestada a assistência à mulher vítima de violência, pelas enfermeiras na atenção primária à saúde (APS), identificam-se as condutas, as dificuldades e possíveis ações de prevenção à saúde da mulher.

\section{MÉTODO}

Trata-se de um estudo exploratório com abordagem qualitativa. Realizado com as enfermeiras da Rede de Atenção Primária do município de Buíque (PE), a $289 \mathrm{~km}$ da capital Recife, entre maio e junho de 2017.

A rede de Atenção Primária (RAS) voltada para a mulher na saúde do município de Buíque-PE conta com dez equipes da Estratégia de Saúde da Família (ESF), sendo três localizadas na zona urbana e sete na zona rural, além de uma maternidade e uma coordenadoria da mulher.

Fizeram parte da população-alvo enfermeiras que trabalham na rede de atenção primária ou da mulher no referido município as quais assinaram o termo de consentimento livre e esclarecido (TCLE). Foram excluídas do estudo duas enfermeiras que participaram do teste-piloto que serviu para verificar a qualidade do instrumento de coleta de dados a fim de avaliar a clareza 
da linguagem e a reprodutibilidade.

Assim, a amostra final foi composta de 11 enfermeiras, oito que fazem parte das ESF da zona urbana e rural, uma da Vigilância Epidemiológica, uma da coordenação da Atenção Primária e uma da Maternidade.

A coleta de dados ocorreu por meio de entrevistas com um roteiro semiestruturado realizado de forma individual, com auxílio de um gravador, a fim de garantir a fidedignidade nos ambientes de trabalhos dos sujeitos da pesquisa. As entrevistas foram transcritas o mais breve possível para que outras impressões presentes na interação fossem preservadas.

$O$ instrumento utilizado durante as entrevistas foi um roteiro semiestruturado constituído de duas partes: uma fechada, abordando a caracterização do profissional, e a outra aberta, com questões norteadoras abordando os aspectos da assistência no serviço de atenção à saúde mulher vítima de violência.

O estudo foi aprovado pelo Comitê de Ética e Pesquisa em Seres Humanos da Autarquia Educacional de Belo Jardim (AEB) por meio do parecer 2.026.253, respeitando os princípios éticos da resolução 466/12, vigente no período de realização da pesquisa.

Os dados sociodemográficos do estudo foram tabulados no EXCEL 2007 e disposto em tabela. Na análise e tratamento dos dados, foi utilizada a orientação da análise de conteúdo, segundo Bardin ${ }^{13}$, que interpreta os dados por meio de três etapas: pré-análise, exploração do material e tratamento dos resultados obtidos e interpretação. Os núcleos temáticos utilizados para a categorização dos dados obtidos se centraram em palavras ou sentidos contidos nas falas dos entrevistados. Foi possível organizar os seguintes núcleos temáticos: contexto da assistência enfermagem e educação continuada.

$\mathrm{Na}$ apresentação dos dados, cada um dos entrevistados foi identificado com a letra E. Em seguida, eles foram numerados para preservar seu anonimato entre 1 e 11 (E1, E2, E3 etc.).

\section{RESULTADOS E DISCUSSÃO}

Conforme Tabela 1, 100\% são do sexo feminino, 45,4 \% com faixa etária acima de 35 anos, 63,6 \% atuam como enfermeiras há menos de seis meses. Quanto à formação profissional e $45,4 \%$ estão formadas há menos de seis anos. Dentre todos os participantes, 45,4\% afirmam que têm especialização em obstetrícia e 36,4 em saúde pública (saúde da família e saúde coletiva).

Tabela 1. Perfil sociodemográfico dos enfermeiros entrevistados

\begin{tabular}{|c|c|c|}
\hline Variáveis & $\mathrm{n}=11$ & $\%$ \\
\hline \multicolumn{3}{|l|}{ Sexo } \\
\hline Feminino & 11 & 100 \\
\hline Masculino & 0 & 0 \\
\hline \multicolumn{3}{|l|}{ IDADE } \\
\hline 20 a 25 & 2 & 18,2 \\
\hline 26 a 35 & 4 & 36,4 \\
\hline$>35$ & 5 & 45,4 \\
\hline \multicolumn{3}{|l|}{ Atuação profissional } \\
\hline$<6$ meses & 7 & 63,6 \\
\hline $6 \mathrm{~m} \mathrm{a} 5$ anos & 4 & 36,4 \\
\hline \multicolumn{3}{|l|}{ Anos de formação } \\
\hline Menos de 6 anos & 5 & 45,4 \\
\hline 6 a 10 anos & 2 & 18,3 \\
\hline+11 anos & 4 & 36,4 \\
\hline \multicolumn{3}{|l|}{ ESPECIALIZAÇÃO } \\
\hline $\begin{array}{l}\text { Saúde pública (SC* } \\
\text { ou } \mathrm{SF}^{* *} \text { ) }\end{array}$ & 4 & 36,4 \\
\hline Obstetrícia & 5 & 45,4 \\
\hline Nenhuma & 2 & 18,3 \\
\hline
\end{tabular}

Fontes: Dados primários, 2017.

A equipe da ESF deve ser multidisciplinar. Dentre essa multidisciplinaridade, deve haver um enfermeiro generalista ou especialista em saúde da família ${ }^{14}$. É essencial que o enfermeiro seja um especialista em saúde da família. Dessa forma, é possível que ele tenha um olhar mais amplo sobre as questões inerentes na comunidade a fim de que seja proporcionada melhor assistência ${ }^{15}$.

Quando questionados sobre se na instituição onde eles trabalham os mesmos já atenderam alguma mulher em situação de violência, eles afirmaram: 
[E1] Sim, já recebi algumas, mas elas não denunciam. Eu percebo através de alguma mancha, espancamento[...].

[E2] Já recebi sim casos de violência verbal, psicológicas, mas foram negadas por elas, as situações e moral. [E9] Não, que ela tenha relatado que sofreu violência. Elas me relatam durante os atendimentos, por exemplo, uma gestante que o marido não permitia fazer determinado exame, ou então agrediu verbalmente[...]Eu fazia os questionamentos com elas e elas me relataram, mas não que a procura do serviço tenha sido por conta da violência.

Conforme relatos dos profissionais, as usuárias não buscam o serviço com o intuito de relatar a violência sofrida e sim a procura de outro atendimento. As equipes da atenção básica enfrentam desafios e dilemas (medos, insegurança) para a construção da atenção integral às mulheres em situações de violências ${ }^{10}$. O silêncio delas sobre as situações de violência está relacionado muitas vezes aos agressores serem seus parceiros íntimos e/ou outros familiares ${ }^{16,17}$.

Sobre a identificação de mulheres que chegam ao serviço de saúde em situação de violência, é crucial que o enfermeiro esteja preparado para identificar os sinais sugestivos de atos violentos, e atento para atuar diante de uma situação de suspeita ${ }^{18}$. As falas destacadas, a seguir, evidenciam os sinais identificados pelos enfermeiros nas mulheres que são vítimas da violência:

[E1] Geralmente eu identifico [...] alguns hematomas, relatando que foi alguma queda ou pancada em algum móvel, e noto que é difícil de bater ou machucar certas partes do corpo onde se encontra as manchas ou hematomas [...].

[E2] [...]Eu identifico através dos ACS's [...]Eu procuro identificar lesões corporais, tentarei identificar alguma agressão psicológica, fazendo o acolhimento e conversando colhendo as informações.

Na maioria dos casos, o Agente Comunitário de Saúde (ACS) é o responsável por identificar situações que sugerem a ocorrência da violência ${ }^{10,15,19}$. Nesse sentindo, é necessário que os profissionais da saúde tenham conhecimento das formas de violência e as identifiquem precocemente, assistam e promovam ações de prevenção e desestímulo à violência. Assim, os profissionais devem estar vigilantes também a sinais que pouco são associados à violência ${ }^{12,20}$.

Ao se interrogar quais profissionais e como eles realizam o atendimento à mulher em situação de violência, observa-se:

[E9] Na unidade em que eu trabalhava esse atendimento à mulher era feito pelo enfermeiro e se caso fosse observado, identificado ou detectado algum tipo de agressão, dependendo do tipo dessa agressão, seguia se um fluxograma dentro da própria unidade que seria encaminhado para um médico e o qual vai fazer todo um histórico e diagnostico e encaminhar para a polícia e orientar a mulher para fazer a denúncia ou não.

[E4] Enfermeiro que vai fazer a consulta de imediato e através dela passar toda a confiança para a mesma, após identificar a violência vai ser prestado todo o atendimento da equipe, médico e outros se necessário.

[E10] Na estrutura de saúde da família participam principalmente o médico, o enfermeiro, e na maioria das vezes os agentes comunitários de saúde que fazem essa grande ponte [...]. O Hospital Regional de Arcoverde é a nossa referência teoricamente falando. [...] Ainda não se tem uma equipe multiprofissional somente preparada, [...]algumas situações pontuais, dentro do município nós temos também através do médico e do enfermeiro nós também determinamos alguns atendimentos. [...] ainda estamos na estruturação da rede. Quando há situações e com a permissão dessa mulher, nós entramos em contato com o psicólogo do município e o CAP. E no momento temos uma ginecologista e obstetra que ele atendem no centro de especialidades $[\ldots]$.

Dessa forma, pode-se verificar na fala dos sujeitos que existe a atuação da equipe das ESF (com destaque para enfermeiro e médico). A primeira assistência às usuárias é fornecida pelo enfermeiro. E de acordo com 
a necessidade são acionados os demais profissionais ${ }^{21}$. Já no hospital, são atendidas pela seguinte ordem: médicos, enfermeiros, psicólogos e assistentes sociais, não necessitando ter que vir em dias diferentes para tais atendimentos ${ }^{22}$.

Os profissionais entrevistados demonstram conhecimento insuficiente sobre as Normas Técnicas para organizar esses atendimentos aos usuários vítimas de violência, culminando com a falta de estrutura na rede de atenção, ou seja de uma assistência efetiva que contemple aspectos individuais, institucionais e sociais. De acordo com as normas do fluxograma de atendimento, as mulheres em situação de violência doméstica e/ ou sexual ${ }^{18}$ deve ser realizado um acolhimento, por meio de uma escuta qualificada com uma equipe multiprofissional; avaliação global (anamnese, o exame físico, o planejamento, a realização da conduta terapêutica e o acompanhamento) ${ }^{20}$ para identificação do tipo de violência e plano de cuidado.

A simplificação da assistência com vista às demandas emergenciais pode conceder uma exposição da usuária, comprometendo a privacidade e consequentemente uma atenção de qualidade ${ }^{20}$. É preciso que o enfermeiro seja capacitado, sobretudo durante sua formação para executar com eficácia o atendimento nas situações de violência qualificando o atendimento e contribuindo para visibilidade da violência ${ }^{12,23}$.

Ao serem questionados sobre quais encaminhamentos são realizados com as usuárias vítimas de violência, foram analisadas algumas inconsistências:

[E5] Eu não as encaminho para lugar nenhum, porque normalmente elas não querem, só converso com elas e tento orientá-las e quando tento encaminhar elas não deixam. Mas uma vez suspeitei de uma criança que a mãe trouxe porque tinha uma pequena lesão e a encaminhei para o Hospital Regional de Arcoverde.

A discursão abaixo se apresentou mais leal ao falar sobre o que foi abordado:

[E10] Até o final do ano passado não tinha muita estrutura para isso não, cada enfermeiros agia dentro do conhecimento que se tinha, [...] pelo município não tem uma conduta es- tabelecida e isto está sendo criado, mais por exemplo, na minha situação de receber violência psicológica eu orientei a vir ao psicólogo. Já orientei a voltar mais vezes a Estrutura de Saúde da Família pode conversar a respeito disso, e geralmente há uma resistência muito grande [...], então das poucas vezes que esses casos mais críticos (mulher vitima de violência sexual) chegaram a mim eu fiz o encaminhamento para o Regional de Arcoverde, esse caso não foi notificado porque a paciente pediu por tudo que não notificasse, e nesses casos que ficamos entre a cruz e a espada.

Observa-se que a conduta adotada pelas enfermeiras nas situações de violência consiste na notificação e no encaminhamento do caso para as unidades de proteção à mulher vítima de violência ${ }^{3}$. É possível observar essas características nos discursos a seguir:

[E6] Depende da gravidade da violência. Em casos leves e moderados é feito a escuta inicial com atendimento individual e a notificação, e acolhimento da vítima a denúncia na delegacia. Em casos graves encaminhamos para o serviço de urgência, e notificar. E em todos os casos encaminhamos para a assistência psicológica.

[E1] Existe uma notificação (Violência a Mulher) que é da epidemiologia, mas só pode ser preenchido quando a mulher quer denunciar o companheiro. Quando é notificado o caso, essa mulher é encaminhada para o Núcleo de Atendimento a Mulher, onde lhe são esclarecidos os seus direitos, lá ela pode prestar queixa, também ficará informada sobre a Lei $\mathrm{n}^{\circ}$ 11.340/06 Maria da Penha.

Ao interpretar a fala da E1, percebe-se que a mesma não está ciente de uma das Normas Técnicas preconizada pelo ministério da Saúde em 2011, que é a notificação compulsória citada. Assim se faz necessária a notificação compulsória, os profissionais de saúde necessitam realizar a notificação desde o momento que há uma suspeita de violência. A notificação é um recurso de total relevância na intervenção dos comportamentos 
violentos. É por meio da notificação que a violência, seja ela de qualquer natureza, ganha visibilidade social e, mais importante ainda, é a partir desta visibilidade que se torna possível o delineamento real dos elementos que compõem ${ }^{12}$. Apesar disso, mesmo com a essencialidade da notificação, os enfermeiros ainda têm dúvidas quanto à sua realização ${ }^{10}$.

O Ministério da Saúde, no ano de 2009, traz a violência doméstica, sexual e/ou outras violências na pauta de doenças e agravos de notificação compulsória ${ }^{24}$. À vista disso, toda e qualquer hipótese ou comprovação de violência, tanto no serviço de atenção primária quanto no hospitalar, deve ser registrada na $\mathrm{FNI}^{3}$. Há também referência com relação aos procedimentos legais, por exemplo, o encaminhamento à delegacia e coleta de exame de DNA para identificação do agressor ${ }^{4}$.

E por fim alguns dos procedimentos que devem ser realizados para atender essas mulheres, que alteram conforme o tipo da violência: em caso de violência sexual - até 72 horas após a ocorrência da violência sexual, iniciar profilaxia das DST/AIDS, hepatite B e de gravidez (SC), orientar no sentido de comparecer à Delegacia de Polícia e fazer acompanhamento com médico e encaminhar para acompanhamento social e psicológico e a notificação. No caso de violência física: comparecer à Delegacia de Polícia para registrar ocorrência e, a partir daí, ser encaminhada ao exame pericial do IML, solicitar retorno e encaminhála para os Programas de Prevenção e Atendimento aos Acidentes e Violências - PAVs - das Regionais, objetivando fortalecer a paciente para que ela saia da dinâmica abusiva, encaminhá-la para acompanhamento social e psicológico e para a Rede Intersetorial - Conselho dos Direitos da Mulher, CREAS, CRAS e serviço de apoio jurídico. Após a denúncia, a mulher terá direito a CasaAbrigo e ao Núcleo de Atendimento às Famílias e Autores de Violência Doméstica e a notificação. Em casos de violência psicológica: orientar para a Rede Intersetorial Conselho dos Direitos da Mulher, CREAS, CRAS e serviço de apoio jurídico, encaminhá-la para acompanhamento psicossocial e a notificação $0^{24}$.

Após terem explanado sobre os procedimentos de atendimento, foram interrogados sobre como é realizado o processo de notificação dos casos atendidos no serviço. Segundo eles,
[E2] É feita a notificação através de uma ficha especifica para casos de violência, que é entregue a vigilância epidemiológica e depois são tomadas as providencias necessárias.

[E3] Através de ficha de notificação de agravo para menores e maiores de idade, que vão para a epidemiologia, e retornarão para arquivar no posto e orientarão sobre que deve se fazer com essa mulher.

[E10] Tem-se uma ficha própria para se fazer o acolhimento do adolescente e da mulher, através de um sistema de informação é emitida essa ficha em que o profissional que acolhe essa pessoa em situação de violência. [...] O enfermeiro ou/o médico, o agente comunitário ele não notifica, apenas sinaliza [...].

Verificou-se similaridade nas respostas dos profissionais entrevistados acerca do conhecimento da existência da ficha de notificação de violência. A prática da notificação é fundamental para o enfrentamento da violência, assim como para assegurar à proteção dos benefícios às mulheres vítimas de violência. Essa atitude proporciona a interrupção do abuso e o desencadeamento da assistência às vítimas e aos seus familiares. ${ }^{10} \mathrm{~A}$ determinação do profissional em conexão com a efetuação ou não da notificação de um caso de violência pode ser vigorosamente motivada pelos aspectos culturais. Sistematicamente, as famílias rejeitam informações que justificam as suspeitas, pois se consideram ameaçadas diante da notificação $0^{25}$.

$\mathrm{O}$ enfrentamento à VCM requer a inserção de inúmeros fatores políticos, legais e, essencialmente, culturais a fim de que seja desnaturalizada pela sociedade, haja vista que se configura como um grande problema de saúde pública.

A lei 10.778 orienta que devem ser notificados os casos de suposição ou confirmação de violência contra a mulher à autoridade sanitária pelos profissionais de saúde (médicos, cirurgiões-dentistas, enfermeiros, auxiliares), bem como a instituição responsável pelo atendimento às vítimas (postos e centros de saúde, institutos de medicina legal, clínicas, hospitais $)^{26}$ em equipamentos públicos ou privados. 


\section{FORTALECIMENTO DA REDE DE PROTEÇÃO}

Com a finalidade de organização da rede de atenção à saúde, as capacitações foram objetos de questionamentos, como se observa nos depoimentos:

[E10] Sim, por vídeo conferência através da VI GERES, curso realmente para instrumentalizar ainda não. Mas há a previsão para este ano de se organizar. E através do Ministério de Saúde conseguimos ter livre acesso para fazermos esse curso. [...] Há a previsão de que venha para VI GERES, para que possa estruturar a rede do município.

[E2] Não fiz curso especifico voltado para vítimas de violência contra a mulher, mas se tratando de saúde da mulher já vi alguns assuntos se tratando da violência contra a mulher. [E2, E3, E4, E 5, E 6, E7 e E 8] Responderam que não.

Os depoimentos sinalizam a necessidade de uma educação continuada para emponderamento dos profissionais, a fim de que seja garantido um atendimento qualificado às vítimas de violência. Neste sentindo são fundamentais as intervenções adequadas junto à população com o objetivo de desencorajar essa prática. ${ }^{27}$

Em relação à articulação com outros serviços da rede de proteção à violência contra a mulher em Buíque$\mathrm{PE}$, os informantes relataram:

[E1] Através da epidemiologia, que é notificado e entregue a ficha, e encaminhado para o núcleo de saúde da mulher onde será informada sobre a lei Maria da penha. O agente comunitário de saúde por ter mais contato com a mulher tenta acompanhar o processo, se a mulher compareceu ou não, se é de menor, que nesse caso é acionado ao conselho tutelar que tem rápidas ações, inclusive temos jovens de 14 a 16 anos que já são mães.

[E5] Não há nenhuma articulação e não vejo nenhuma integração.

[E9] Conselho tutelar e delegacia estão bem desarticulados. Realmente não existe uma boa integração. Eu sei aqui no município existe uma coordenação da mulher, não existe uma delegacia especifica para mulher, então pode ser um dos fatores que essa mulher nem procure nem realize a denúncia e[...].

[E3, E4, e E5] Não souberam informar.

Observa-se que no município não há integração intersetorial entre a rede. De acordo com a Norma Técnica para Prevenção e Tratamento dos Agravos consequentes da violência sexual contra mulheres e adolescente, o campo da saúde pode significar um dos territórios beneficiados para identificação, definição e articulação de serviços que operam nesta atenção. Deve-se destinar aos gestores municipais e estaduais a atribuição de organizar as redes integradas de atendimento na capacitação de recursos humanos, na publicação da rede e no fornecimento de insumos ${ }^{12}$. A despeito das iniciativas e propostas, as ações dos serviços de saúde não conduziram a perspectiva de atenção integral com a articulação em rede. São diversos estudos que perceberam, tanto em nível de atenção primária, secundária e terciária dificuldades e inexistência de articulações intersetoriais ${ }^{28}$.

Diante disso, os sujeitos da pesquisa foram convidados a falar sobre as dificuldades e facilidades encontradas no serviço no atendimento às mulheres em situação de violência:

[E2] A grande dificuldade encontrada é o medo que elas sentem de assumir a violência, muitas das vezes querem proteger os parceiros por dependerem financeiramente deles[...]. O que facilita são os ACS's que já trazem para mim um bom diagnóstico.

[E5] As dificuldades são porque nós trabalhamos numa comunidade há anos, então de certa forma estamos lá todo dia[...]como ela quer, não vamos mexer, porque é um caso que ele não é uma peça boa, então nós ficamos receosa em fazer a denúncia as exceções, [...]Não vejo facilidades, mas o que ajuda é meu entrosamento com a equipe.

[E10] Aspectos que facilitam esse atendimento $[. .$.$] é que elas tem uma$ livre demanda, o fato delas chegarem no PSF muitas vezes como não tem um dia pontual. [...]Demanda espontânea ou como outro tipo de serviço e acaba trazendo a situação para nós. [...]Não há material adequado, estrutura física adequada, os exames todos necessário, as medicações todas englobam muitas vezes necessária ter uma referência de fato 
para poder garantir a estabilidade da vida dela inclusive segurança, não se tem um jurídico efetivo nessa situação, não tem uma casa de passagem, um abrigo que possa facilitar essa situação [...].

As dificuldades são muitas e é fundamental que medidas sejam implantadas para transformar esse cenário, colaborando para a qualidade de vida e a melhoria na assistênciát. A principal delas retoma as temáticas éticas associadas ao reconhecimento e respeito à independência dos sujeitos e ao dever dos profissionais de saúde em eventos que tragam risco a outras pessoas ou a si mesmos ${ }^{24}$. Entretanto, encontram-se vários entraves que o enfermeiro enfrenta para discutir e intervir na situação de violência $^{12}$. É comum o ACS ser o facilitador por identificar incidente que sugere a ocorrência da violência. ${ }^{29}$

Apesar das complexidades e incomplexidades, ainda assim existem algumas ações de prevenção que são realizadas no serviço em caso de violência contra a mulher.

[E1] Palestra e orientações aos agentes de saúde que passam nos domicílios e orientem essas mulheres. Eu sempre falo da forma como elas devem ser tratadas, mas também como elas devem tratar seus companheiros, porque quem dar respeito quer respeito.

[E7] [...]Realiza-se apenas palestras e conscientização das mulheres em denunciar e procurar os serviços que podem ajudar, mas na minha opinião, este tema é pouco trabalhado e subnotificado nas unidades de Saúde.

[E9] [...]Esporadicamente são campanhas educativas dentro do programa de saúde da mulher, e também nas consultas ou até nas citologias $[\ldots]$.

É notória a limitação para o desenvolvimento de ações que são exibidas para as pacientes, por meio de palestras, campanhas e orientações. E para trabalhar essas questões referentes à violência e solucionar os obstáculos vistos, é preciso adotar as ações de promoção do cuidado e de prevenção de riscos e agravos, dispor de discussões em relação às questões vistas, vincular as linhas de cuidado integral que melhorem os serviços de saúde, possibilite o diálogo das ações com as políticas públicas e com outros setores da rede de atenção, contribuindo assim para proporcionar a proteção e o cumprimento dos direitos das mulheres vítimas de violência ${ }^{10,27}$.

$O$ enfermeiro enfrenta diversos desafios ao trabalhar com a violência: requer um olhar diferenciado, a família que muitas vezes não quer expor a mulher e nem se expor, a falta de capacitação dos profissionais e a responsabilidades de atribuições. Tudo isso é capaz de contribuir para a subnotificação dos casos. As condutas de prevenção da violência precisam ser trabalhadas sempre que viável, pois essa é uma adversidade que afeta toda a sociedade. Assim, a luta contra os comportamentos violentos deve ser incentivada dentro de toda e qualquer sociedade ${ }^{4}$.

Os limites deste estudo estão relacionados à apresentação de dados de uma região, que representam o contexto da APS do município em estudo, acerca dos atendimentos das mulheres em situação de violência. No entanto, mesmo não sendo possível generalizar, os resultados retratam a invisibilização da VCM no contexto da APS, cenário que se repete nas demais regiões do país.

\section{CONSIDERAÇÕES FINAIS}

Os dados evidenciaram: limitações no preparo dos profissionais das ESF (porta de entrada para essas vítimas da violência) ao prestar o atendimento a essas pacientes, falta de estrutura dos recursos humanos e materiais e de uma rede de proteção para as mulheres vítimas de violência, problema este que tem sido deixado de lado.

Ao conhecer a percepção dos profissionais de saúde em relação ao cuidado à mulher em situação de violência, percebe-se certo distanciamento e um evidente sofrimento em atender uma demanda de complexidade ímpar. Faz-se necessário que os serviços de saúde dêem maior ênfase ao combate e à prevenção da violência, possibilitando assim a melhoria da assistência prestada ao cliente e aumentando o incentivo à cultura de paz.

Para as profissionais entrevistadas, sugerese a realização de capacitação sobre violência e sobre 
as formas de prevenção, a promoção do acolhimento solidário e o encorajamento da notificação promovendo a intervenção profissional humanizada capaz de garantir os direitos à autonomia e autoestima da mulher vitimizada. Negligenciar esses aspectos representa descaso ou abandono.

\section{REFERÊNCIAS}

1. World Health Organization (WHO). Global consultation on violence and health.Violence: a public health priority. Geneva: WHO; 1996 (Document WHO/EHA/ SPI.POA.2).

2. Organização Mundial da Saúde (OMS). Relatório mundial sobre a prevenção da violência 2014. Núcleo de Estudos da Violência da Universidade de São Paulo. Disponível em: < http://nevusp.org/wpcontent/uploads/2015/11/1579-VIP-Main-report-PtBr-26-10-2015.pdf> . Acesso em: 30 maio 2018.

3. Waiselfisz JJ. Mapa da Violência 2015: Homicídio de Mulheres no Brasil Atualização. FLACSO, 2015. p. 1112.

4. Fórum Brasileiro de Segurança Pública. Anuário Brasileiro de Segurança Pública n. 11. 2017. Disponível em: <http://www.forumseguranca.org. br/wpcontent/uploads/2017/12/ANUARIO_11_2017. pdf. Acesso em: 05 mar. 2018.

5. Vicente DM, Tamaturgo DS, Martins RBM, Carvalho KB, Queiroz KT. Mortalidade como conseqüência da violência contra a mulher: um levantamento de dados. 2017. Disponível em: <http://enfermagem. crearecenter.com/conta/imagens/uploads/17MORTALIDADECOMOCONSEQU_NCIADAVIOL NCIACONTRAAMULHER.pdf $>$. Acesso em: $20 \mathrm{fev}$. 2018.

6. Guedes RN, Fonseca RGS, EGRY, Emiko Y. Limites e possibilidades avaliativas da estratégia saúde da família para a violência de gênero. Rev. esc. enferm. USP [online]. 2013; 47(2):304-311.
7. Lettiere A, Nakano MAS. Rede de atenção à mulher em situação de violência: os desafios da transversalidade do cuidado. Rev Eletr Enf [Internet]. 2015; 17(4): 1824. Disponível em: < https://www.fen.ufg.br/revista/ v17/n4/pdf/v17n4a18.pdf $>$. Acesso em: 30 maio 2018.

8. Minayo MCS, Njaine K, Assis SG, Constantino P. (Org.). Impactos da Violência na Saúde. Fundação Osvaldo Cruz. Educação a Distância da Escola Nacional de Saúde Pública de Sérgio Arouca. Rio de Janeiro: Fiocruz; 2010. p. 22.

9. Costa DAC, Marques JFM, Moreira KAP, Gomes LFDS, Henriques ACPT, Fernandes AFC. Assistência multiprofissional à mulher vítima de violência: atuação de profissionais e dificuldades encontradas. Cogitare enferm. 2013 abr/jun; 18(2):302-9.

10. Silva NNF, Leal SMC, Trentin D, Vargas MAO, Vargas CP, Vieira LB. Atuação dos enfermeiros da atenção básica a mulheres em situação de violência. Enferm. Foco. 2017; 8(3):70-4.

11. Feitosa ALX, Albuquerque, CM, Cariri, LS, Anjos YYF, Vargas MM. Atendimento a mulher que sofre violência doméstica na Estratégia de Saúde da Família. International nursing congress theme: good practices of nursing representations in the construction of society. May 9-12, 2017.

12. Moreira TNF, Martins CL, Feuerwerker LCM, Schraiber LBA. A construção do cuidado: o atendimento às situações de violência doméstica por equipes de Saúde da Família. Saúde Soc. São Paulo. 2014; 23(3); 814-27.

13. Bardin L. Análise de Conteúdo. 3. ed. São Paulo, SP: $70 ; 2004$.

14. Brasil. Aprova a Política Nacional de Atenção Básica, estabelecendo a revisão de diretrizes e normas para a organização da Atenção Básica. Portaria nº 2.436, de 21 de setembro de 2017. [Internet]. Brasília: Ministério da Saúde; 2017. Disponível em: < http:// pesquisa.in.gov.br/imprensa/jsp/visualiza/index. jsp?jornal $=1 \&$ pagina $=68 \&$ data $=22 / 09 / 2017$. Acesso em: 01 jun 2018. 
15. Galindo NAL, Gonçalves CFG, Neto MNG, Santos SC, Santana SCS, Alexandre ACS. Violência infantojuvenil sob a ótica da enfermagem. Rev. enferm ufpe online. Recife. 2017;11(Supl. 3):1420-9.

16. Osis MJD, Duarte GA, Faúndes A. Violência entre usuárias de unidades de saúde: prevalência, perspectiva e conduta de gestores e profissionais. Rev. Saúde Pública. 2012 ;46 (2):351-8.

17. Broch D, Crossetti MGO, Riquinho DL. Reflexões acerca da violência contra a mulher na ótica de Madeleine Leininger. Rev enferm UFPE on line. 2017;11(12):5079-84.

18. Galindo NAL, Alexandre ACS, Gonçalves CFG. Violência infanto-juvenil sob a ótica da enfermagem. Rev enferm UFPE online [Internet]. 2017; 11(Supl. 3):1420-9.

19. Garbin CAS, Rovida TAS, Costa AA, Garbin AJI. Reconhecimento e notificação de violência pelos profissionais da estratégia de saúde da família Arch Health Invest .2016; 5(1): 8-12. Disponível em: < http://dx.doi.org/10.21270/archi.v5i1.1294. Acesso em: 30 jun 2018.

20. Lima MCCS, Nascimento OC, Alves TDB, Bigras M, Costa COM, Silva MR. Atuação profissional da atenção básica de saúde face à identificação e notificação da violência infanto-juvenil. RBSP [Internet]. 35(Supl.1): 118-37. Jan/Jun 2011. Disponível em: < http://files. bvs.br/upload/S/01000233/2011/v35nSupl1/a2303. pdf > acesso em: 07 jun 2017.

21. Lima SLL. Os profissionais de saúde e a atenção à mulher em situação de violência sexual: um estudo nos serviços de referência do município de Natal/ Rio Grande do Norte. (Dissertação de Mestrado). Rio de Janeiro: Escola Nacional de Saúde Pública Sergio Arouca; 2013. Disponível em: <http://bvssp.icict. fiocruz.br/lildbi/docsonline/get. $\quad$ php?id=3514 $>$. Acesso em: 07 jun 2017.

22. São Paulo (BR). Violência Sexual. Normas e rotina para o atendimento das vitimas de violência sexual. $1^{\circ}$ ed. São Paulo, Junho 2012; p.12.
23. Ministério da Saúde (BR). Prevenção e Tratamento dos Agravos Resultantes da Violência Sexual contra Mulheres e Adolescentes: Norma Técnica. 3. ed. Brasília(DF): Ministério da Saúde; 2012.

24. Aragão AS, Ferriani MGC, Vendruscollo TS, Souza SL, Gomes R. Abordagem dos casos de violência à criança pela enfermagem na atenção básica. Rev Latino-Am Enfermagem. 21(Spec): [07 telas]. Jan/ fev 2013. Disponível em: < http://www.arca.fiocruz. br/bitstream/icict/6691/2/pt_22.pdf > . Acesso em: 09 jun. 2017.

25. Cross TP, Mathews B, Tonmyr L, Scott D, Ouimet C. Child welfare policy and practice on childrens exposure to domestic violence. Child Abuse Negl.2012; 36(1): 210-6. Disponível em: <https:// www.ncbi.nlm.nih.gov/pubmed/22425164>. Aceso em: 10 jun. 2017.

26. Lise F, Motta MGC. Violência doméstica infantil: abordagem da enfermagem. Acta Sci Health Sci. 2012;34(1):53-8. Disponível em: < http://periodicos. uem.br/ojs/index.php/ActaSciHealthSci/article/ view/9268/pdf $>$ Acesso em: 10 jun. 2017.

27. Coelho BSE. Atençãoa homens e mulheres em situação de violência por parceiros íntimos. Florianópolis: Universidade Federal de Santa Catarina, 2015:298317. Disponível em: https://unasus-cp.moodle.ufsc. br/enrol/index.php?id=49 Acesso em: 9 mar. 2017.

28. Lobato GR, Moraes CL, Nascimento MC. Desafios da atenção à violência doméstica contra crianças e adolescentes no Programa Saúde da Família em cidade de médio porte do Estado do Rio de Janeiro, Brasil. Cad. Saúde Pública. 2012; 28(9):1749-58. Disponível em: <http://www.scielosp.org/pdf/csp/ v28n9/v28n9a13.pdf> . Acesso em: 11 jun. 2017.

29. Hesler LZ, Costa MC, Resta DG, Colomé ICS. Violência contra as mulheres na perspectiva dos agentes comunitários de saúde. Rev Gaúcha Enferm. 2013;1(34): 180-6.

Recebido em: 11/03/2018 Aceito em: 06/06/2018 